\title{
Studies on Preparation and Preservation of Ready-To-Serve (RTS) Beverage from Underutilized Mulberry (Morus alba L.) Fruits and Its Quality Evaluation during Storage
}

\author{
Hamid", N.S. Thakur, Pradeep Kumar and Abhimanyu Thakur \\ Department of Food Science and Technology, Dr YS Parmar University of \\ Horticulture and Forestry, Nauni, Solan, HP 173230, India \\ *Corresponding author
}

\begin{tabular}{|c|c|}
\hline & A B S T R A C T \\
\hline & \multirow{10}{*}{$\begin{array}{l}\text { The present investigations were conducted to develop RTS beverage from nutritious } \\
\text { underutilized mulberry (Morus alba L.) fruits. Different combinations of juice }(8 \%, 10 \% \text {, } \\
12 \%, 14 \% \text { and } 16 \%) \text { and TSS }\left(12{ }^{\circ} \mathrm{B} \text { and } 15{ }^{\circ} \mathrm{B}\right) \text { were tried to standardize proper } \\
\text { combination for RTS beverage with constant acidity }(0.30 \%) \text {. Out of ten treatments, } \\
\text { recipe } \mathrm{T}_{4}(14 \% \text { juice }+12 \mathrm{~B} \text { TSS+0.30 \% acidity) was found to be the best on the basis of } \\
\text { physico-chemical characteristics like reducing sugars }(7.90 \%) \text {, total sugars }(10.27 \%) \text {, pH } \\
(4.10) \text {, ascorbic acid }(1.87 \mathrm{mg} / 100 \mathrm{ml}) \text {, anthocyanins }(2.90 \mathrm{mg} / 100 \mathrm{ml}) \text {, total phenols } \\
(21.16 \mathrm{mg} / 100 \mathrm{ml}) \text { and with highest sensory scores as colour }(8.00) \text {, body }(7.90) \text {, taste } \\
(8.10) \text {, aroma }(7.90) \text { and overall acceptability ( }(7.95) \text { for the preparation of RTS beverage. } \\
\text { Further standardized product was packed in PET (polyethylene terephthalate) and glass } \\
\text { bottles under ambient and refrigerated storage. Minimum decrease was recorded in various } \\
\text { chemical characteristics like titratable acidity }(0.30 \text { to } 0.25 \%) \text {, anthocyanins }(2.90 \text { to } 1.89 \\
\text { mg/100 ml), total phenols }(21.16 \text { to } 16.88 \mathrm{mg} / 100 \text { ml and increase in total sugars }(10.27 \\
\text { to } 11.19 \%) \text { was observed after } 6 \text { months of storage. Drink could be stored safely for a } \\
\text { period of } 6 \text { months; however quality of the product was retained better in glass than PET } \\
\text { bottles stored under refrigerated conditions as compared to ambient storage conditions. }\end{array}$} \\
\hline Keywords & \\
\hline & \\
\hline & \\
\hline $\begin{array}{l}\text { An } \\
\text { Phe }\end{array}$ & \\
\hline & \\
\hline Arti & \\
\hline & \\
\hline & \\
\hline & \\
\hline
\end{tabular}

\section{Introduction}

Mulberry (Morus alba L.) an underutilized fruit is known as shahtut, tut, chinni and tutri in Himachal Pradesh (HP). This genus is widely distributed in Asia, Africa, Europe, South and North America. It is also widely found in hilly areas of Himalayas up to 3300 $\mathrm{m}$ elevation (Zafar et al., 2013). Among various Morus species Morus alba L. has been cultivated widely in Asia especially in China, Japan and India for rearing silkworms besides fruit purpose (Ercisli and Orhan, 2007). Its fruits contain essential fatty acids, vitamins, polyphenols, carbohydrates, fibre, minerals, riboflavin, ascorbic acid, carotene and nicotinic acid (Chon et al., 2009).

Juices are a good source of sugars, vitamins, and minerals; all valuable components to human health. The current food trend toward healthier diets makes juice consumption an important natural food alternative and improves the availability of its nutritive compounds. Fruit, vegetable or herbal juices could play an important role in enhancing 
human health (Pushpa et al., 2016). Mulberry juice is full of antiaging properties and enriches the blood, protecting liver from damage, calms the nerves, balances internal secretions and enhances immunity (Yadav et al., 2014) . The small edible fruits with attractive colour are sweet which can be consumed fresh and can also be processed into various fruit products. Short shelf life of fresh fruits after harvest is one of the major factors that give the necessity of developing a cheap and efficient preservation process or value-addition for growers of this fruit. Due to Short shelf life very less work on processing of this fruit has been reported so far in India. In HP more emphasis has been given for its use in silkworm rearing, not on the fruits, as a result the fruits goes waste.

The nutritive value of fruit beverages is much more than the synthetic products, which are available in the market throughout the country. If synthetic drinks can be substituted with the fruit juice, it would be beneficial to the consumers as well as fruit growers. Looking to the demand of natural beverages, there is great scope for the preparation of juices and other fruit based beverages (Gupta et al., 2015). Therefore, being a rich source of antioxidants especially phenols, the present studies were under taken with the objective to develop RTS beverage from this underutilized mulberry fruit and to study effect of storage on its chemical constituents.

\section{Materials and Methods}

\section{Standardization of the recipe for the development of RTS beverage}

The mature fruits of Morus alba were procured from Bela area of Hamirpur district of Himachal Pradesh in the month of April and used for various physico-chemical analysis and juice extraction. The juice from the mulberry fruits after washing with water was easily extracted by using hydraulic press machine. Extracted juice was heated once until boiling before its addition into the sugar syrup. Sugar syrup was prepared by adding required amount of sugar into measured quantity of water, followed by boiling with the addition of required amount of citric acid and then straining with muslin cloth to remove impurities. Then mixing of juice and syrup was done in different proportions followed by homogenization and addition of synthetic colour carmosine $(0.002 \%)$ in all treatment combinations. Homogenized product divided into two equal lots (with and without addition of sodium benzoate 120 $\mathrm{ppm})$. Prepared product then hot filled into pre-sterilised glass (heat sterilized) bottles (200 ml capacity) followed by corking and heat processing for 30 minutes. Sodium benzoate $(120 \mathrm{ppm})$ was added at the end of product preparation of drink packed in PET bottles (200 $\mathrm{ml}$ capacity). All the packed products were properly labelled and stored in ambient $\left(20-25^{\circ} \mathrm{C}\right)$ and refrigerated temperature $\left(4-7^{\circ} \mathrm{C}\right)$ conditions for six months.

Fruit drink was prepared by mixing different proportions of Morus alba juice in different concentrations of sugar syrup as given in table 1. The chemical characteristics of the prepared product were estimated at zero, three and six months of storage.

\section{Physico-chemical analysis}

The colour of drink in terms of red (R) and Yellow (Y) units was observed with Tintometer (Lovibond Tintometer Model-E). TSS $\left({ }^{\circ} \mathrm{B}\right)$, titratable acidity $(\%)$, sugars $(\%)$, ascorbic acid $(\mathrm{mg} / 100 \mathrm{ml})$ and anthocyanins $(\mathrm{mg} / 100 \mathrm{ml})$ of prepared products were determined according to methods described by Ranganna (2009). The $\mathrm{pH}$ of the samples was determined by using a digital $\mathrm{pH}$ meter (CRISON Instrument, Ltd, Spain). Total 
phenols $(\mathrm{mg} / 100 \mathrm{ml})$ content was determined by Folin-Ciocalteu procedure given by Singleton and Rossi (1965).

\section{Sensory evaluation}

Nine points hedonic rating test was followed for conducting the sensory evaluation of mulberry drink as explained by Amerine et al., (1965). The panel of ten judges was selected to evaluate the product for sensory parameters such as colour, body, taste, aroma and overall acceptability.

\section{Statistical analysis}

Data on physico-chemical characteristics of squash was analysed by Completely Randomized Design (CRD) before and during storage, whereas, data pertaining to the sensory evaluation were analyzed by using Randomized Block Design (RBD) as described by Mahony (1985). The experiments on recipe standardization and for storage studies were replicated three times.

\section{Results and Discussion}

Standardization of recipe for the development of mulberry drink

The data pertaining to physico-chemical and sensory characteristics of mulberry drink prepared by following different recipes are presented in tables 2 and 3 .

\section{Physico-chemical characteristics of different recipes}

Data pertaining to physico-chemical characteristics of different recipes of mulberry drink presented in table 2 . From the results it was found that with the increase in juice content in different recipes a significant effect on physico-chemical characteristics of mulberry drink recipes was observed. Data presented in table 2 shows that recipe $T_{1}$ and $\mathrm{T}_{6}$ contain less content of anthocyanins, total phenols and ascorbic acid, it might be due to less percentage of juice used as compared to other recipes like $T_{5}$ and $T_{10}$, which contain higher content of anthocyanins, total phenols and ascorbic acid because of higher percentage of juice used in these recipes. The change in juice content in different recipes has also affected the colour units of the drink.

Data given in table 3 shows that there was significant effect of juice-acid-syrup blend on sensory scores of different recipes of mulberry drink. The higher colour and body scores for recipes $T_{4}$ and $T_{9}$ might be due to better combination of juice-syrup blend as compared to other recipes. The changes in juice content in different recipes have also affected the taste and aroma scores of the drink. The recipe $\mathrm{T}_{4}$ obtained the highest taste and aroma scores which may be due to the higher juice content used, better sugar-acidjuice blend in this recipe of mulberry drink. The higher overall acceptability scores for recipe $\mathrm{T}_{4}$ might be due to better combination of juice-acid-syrup blend as compared to other recipes.

From the above results it was concluded that the recipe with 14 per cent juice, 0.30 per cent acidity and $12{ }^{\circ} \mathrm{B}$ TSS ( $\left.\mathrm{T}_{4}\right)$ was found to be the best on the basis of sensory and some physico-chemical characteristics of the drink.

\section{Physico-chemical and sensory characteristics of standardized recipe of mulberry drink}

From the results it was observed that this standardized recipe of mulberry drink (Table 4) contained relatively higher ascorbic acid, total phenols and anthocyanins contents along with best sugar acid blend, which is because of higher content of fruit juice used in this recipe. This recipe also obtained maximum 
scores for sensory parameters like colour, body, taste, aroma and overall acceptability, which may be due to higher juice content, best combination of juice and syrup, best sugar-acid blend in the product and finally all these factors might have led the judges to award the highest scores to this recipe.

\section{Effect of storage on chemical constituents of mulberry drink}

\section{Colour}

Data of visual colour of drink measured by tintometer colourimeter in the form of red and yellow TCU. The overall effect of storage period on the red TCU of drink indicates that they decreased from 5.60 to 5.30, while, on the yellow TCU of drink indicate that they decreased from 0.40 to 0.35 . The overall effect of storage conditions and packaging material on yellow TCU of drink was found to be non-significant. The reason for decrease in colour units of drink during storage might be due to degradation of anthocyanin pigments. However, these pigments degraded at slower rate at low temperature hence there was less decrease in refrigerated conditions. Minimum decrease observed in colour units of drink packed in glass bottle than PET bottle because of slower rate of chemical reactions in product packed in glass bottle as a result of difference in their thermal conductance properties.

\section{TSS}

The TSS content of mulberry drink increased slightly during storage and this increase in TSS during storage might be due to hydrolysis of polysaccharides into monosaccharide and soluble disaccharides. The overall effect of storage conditions shows that higher TSS $\left(12.44{ }^{\circ} \mathrm{B}\right)$ was observed in ambient storage conditions as compared to refrigerated storage conditions $\left(12.20{ }^{\circ} \mathrm{B}\right)$.
More increase in TSS was found in drink stored under ambient conditions (Increased from 12 to 12.70 and $12.85{ }^{\circ} \mathrm{B}$ in both glass and PET) as compared to refrigerated storage conditions (Increased from 12 to 12.35 and $12.40{ }^{\circ} \mathrm{B}$ in both glass and PET) and this might be due to the faster rate of reaction because of high temperature in ambient conditions. These results are also in conformity with the findings of Chavan et al., (2011) in pomegranate RTS beverage and Chalke et al., (2012) in mango RTS beverage

\section{Apparent viscosity}

Apparent viscosity of mulberry drink in terms of flow rate increased significantly during the storage period. The overall effect of storage period on apparent viscosity of drink indicates that it increased from 83.20 to 87.50 (flow rate in seconds). More increase was found in drink stored under ambient conditions (Increased from 83.20 to 88.00 and $89.00{ }^{\circ} \mathrm{B}$ in both glass and PET) as compared to refrigerated storage conditions (Increased from 83.20 to 86.00 and $87.00{ }^{\circ} \mathrm{B}$ in both glass and PET).

Increase in apparent viscosity may be due to the increase in TSS and soluble sugars which increased strain and shearing rate and decreased the flow index of the product. As the flow index decreases it helps to develop pseudo plasticity and increased the apparent viscosity. Similar results have been reported by Jain et al., (1996) in mango RTS beverage.

\section{Titratable acidity}

Figure 1 indicates that there was a general decreasing trend in the titratable acidity of mulberry drink during entire storage period of six months. The overall effect of storage period shows that, acidity of drink decreased from 0.30 to 0.25 per cent during storage irrespective of packaging materials and 
storage conditions. The overall effect of storage conditions as well as packaging materials on acid content of drink found to be non-significant.

The decrease in titratable acidity of drink might be due to co-polymerization of organic acids with sugars and amino acids. Our results are in conformity with the findings of Bisht et al., (2008) in seabuckthorn drink, Rajanna and Shivanna (2008) in mango drink and Satkar et al., (2015) in bitter gourd drink.

\section{pH}

The $\mathrm{pH}$ of drink showed a slight increase during storage which might be due to the more degradation of acid in the product during storage. More increase in $\mathrm{pH}$ was found in drink stored under ambient conditions (Increased from 4.10 to 4.19 and $4.21{ }^{\circ} \mathrm{B}$ in both glass and PET) as compared to refrigerated storage conditions (Increased from 4.10 to 4.14 and $4.16{ }^{\circ} \mathrm{B}$ in both glass and PET) The findings of present studies are in agreement with the results of earlier investigations reported by Kannan and
Thirumaran (2002) in jamun drink and Chalke et al., (2012) in mango RTS beverage..

\section{Reducing sugars}

During storage of mulberry drink, there was a gradual increase in reducing sugars. However, more increase in reducing sugars was found in drink stored under ambient conditions (Increased from 7.90 to 8.86 and $9.12{ }^{\circ} \mathrm{B}$ in both glass and PET) as compared to refrigerated storage conditions (Increased from 7.90 to 8.40 and $8.82{ }^{\circ} \mathrm{B}$ in both glass and PET). Increase in sugars during storage might be attributed due to the hydrolysis of starch into sugars and more increase might be due to the faster rate of reactions because of high temperature in ambient conditions. As far as the packaging material is concerned, more increase in sugars recorded in drink packed in PET bottle as compared to glass bottle might be due to faster rate of chemical reactions in the product packed in PET bottle as a result of their thermal conductance properties. Similar results have been reported by Chalke et al., (2012) in mango RTS beverage.

Fig.1 Effect of packaging and storage on titratable acidity (\%) of mulberry drink

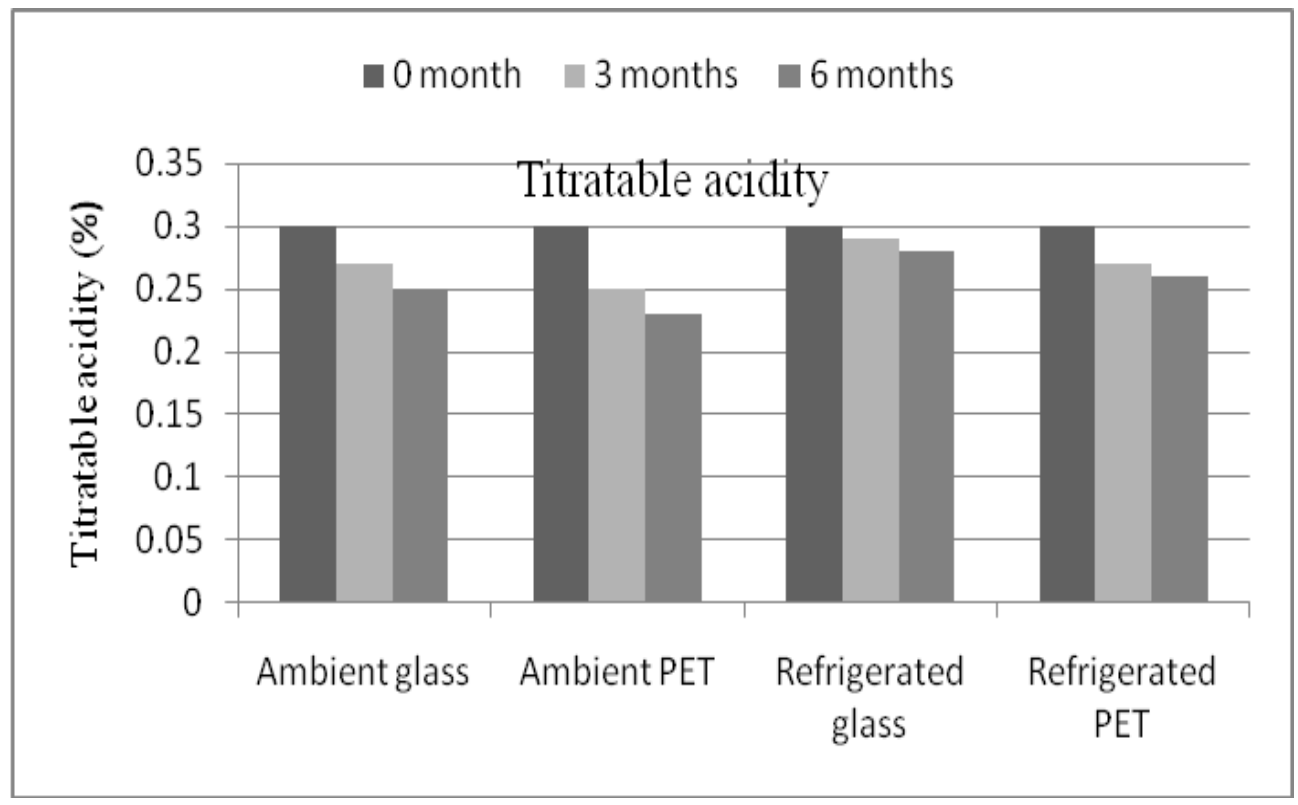


Fig.2 Effect of packaging and storage on Total sugars content of mulberry drink

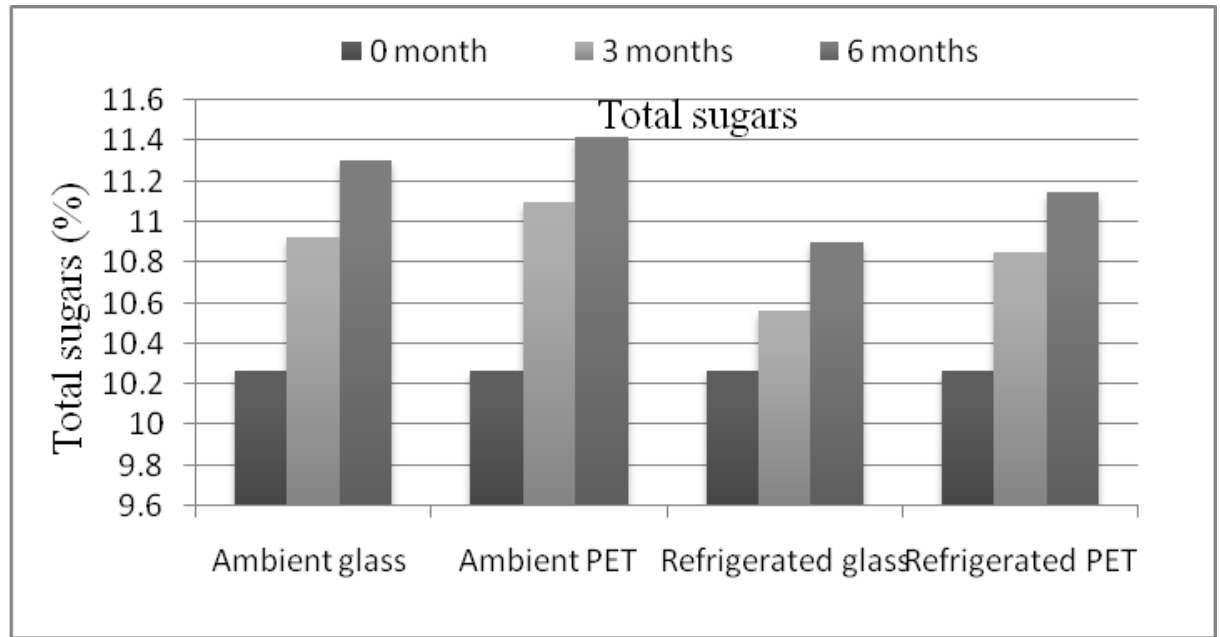

Fig.3 Effect of packaging and storage on anthocyanins content of mulberry drink

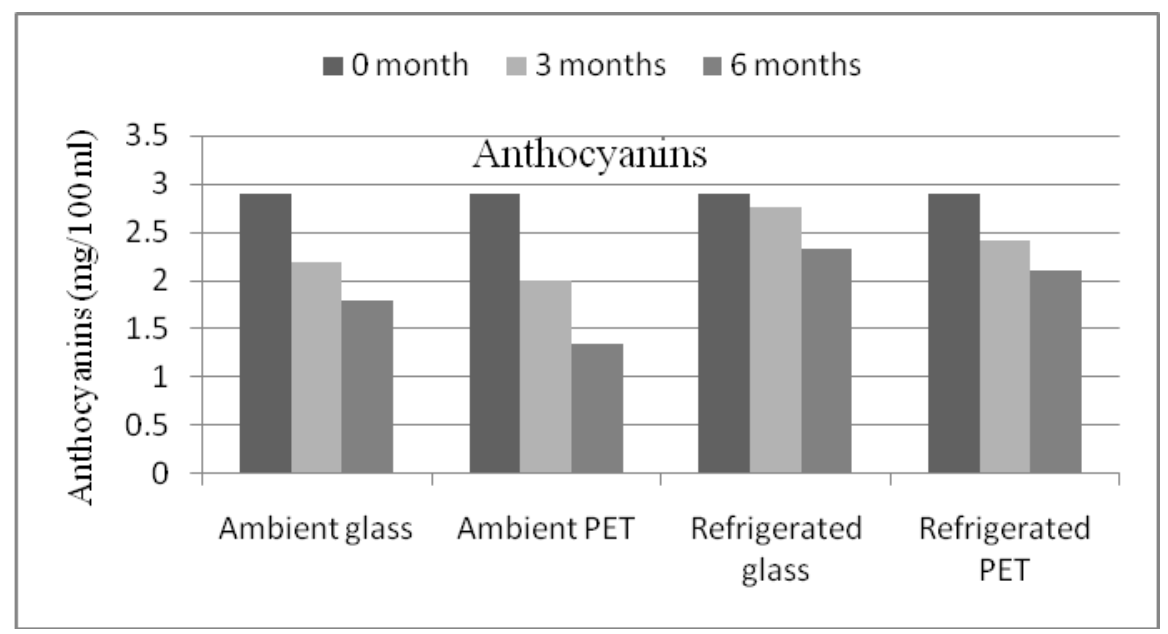

Fig.4 Effect of packaging and storage on total phenolics of mulberry drink

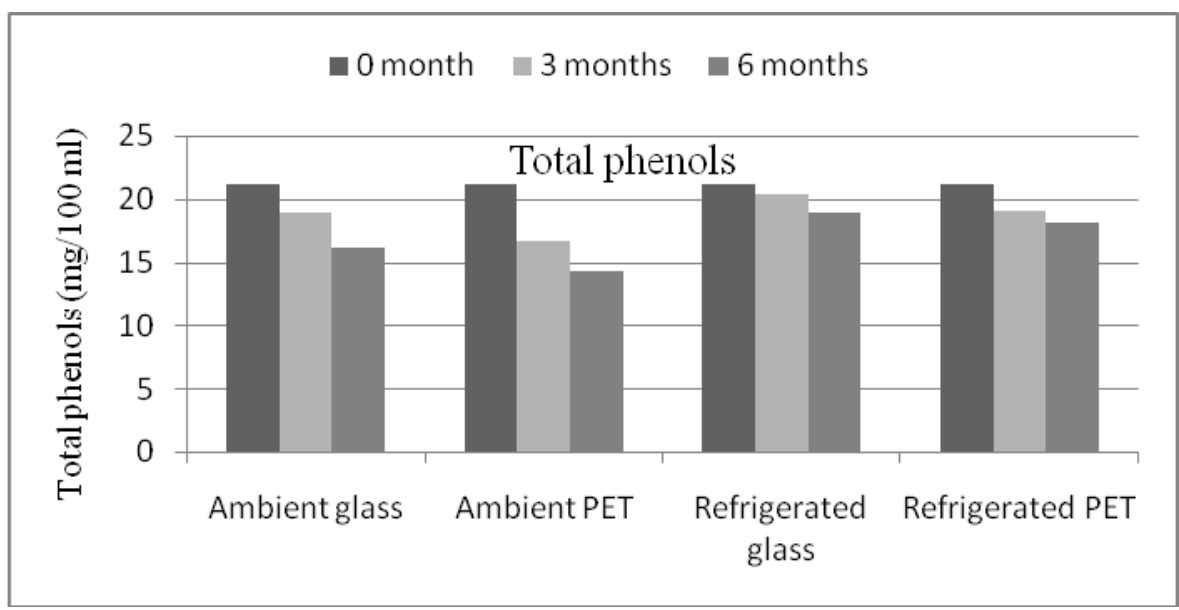


Fig.5 Effect of storage on sensory characteristics of mulberry RTS beverage stored in glass and PET bottles under ambient storage conditions

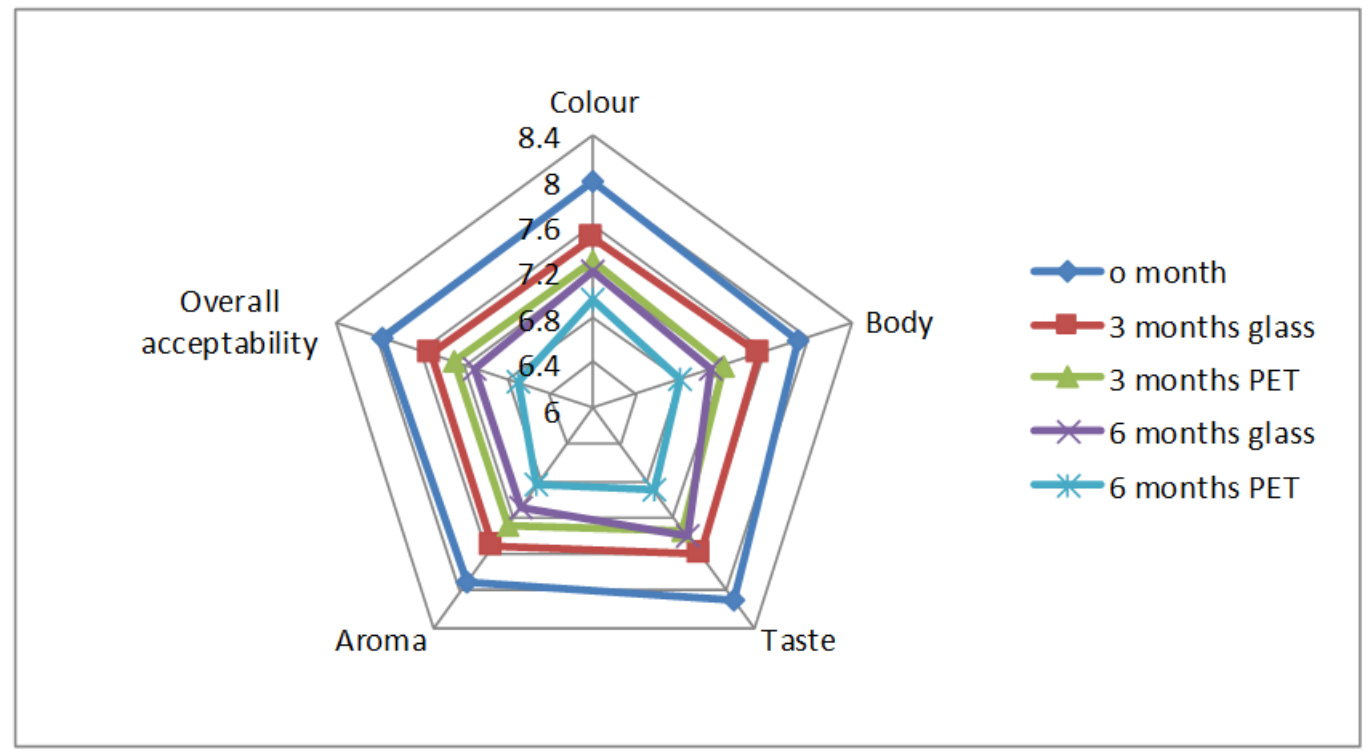

Fig.6 Effect of storage on sensory characteristics of mulberry RTS beverage stored in glass and PET bottles under refrigerated storage conditions

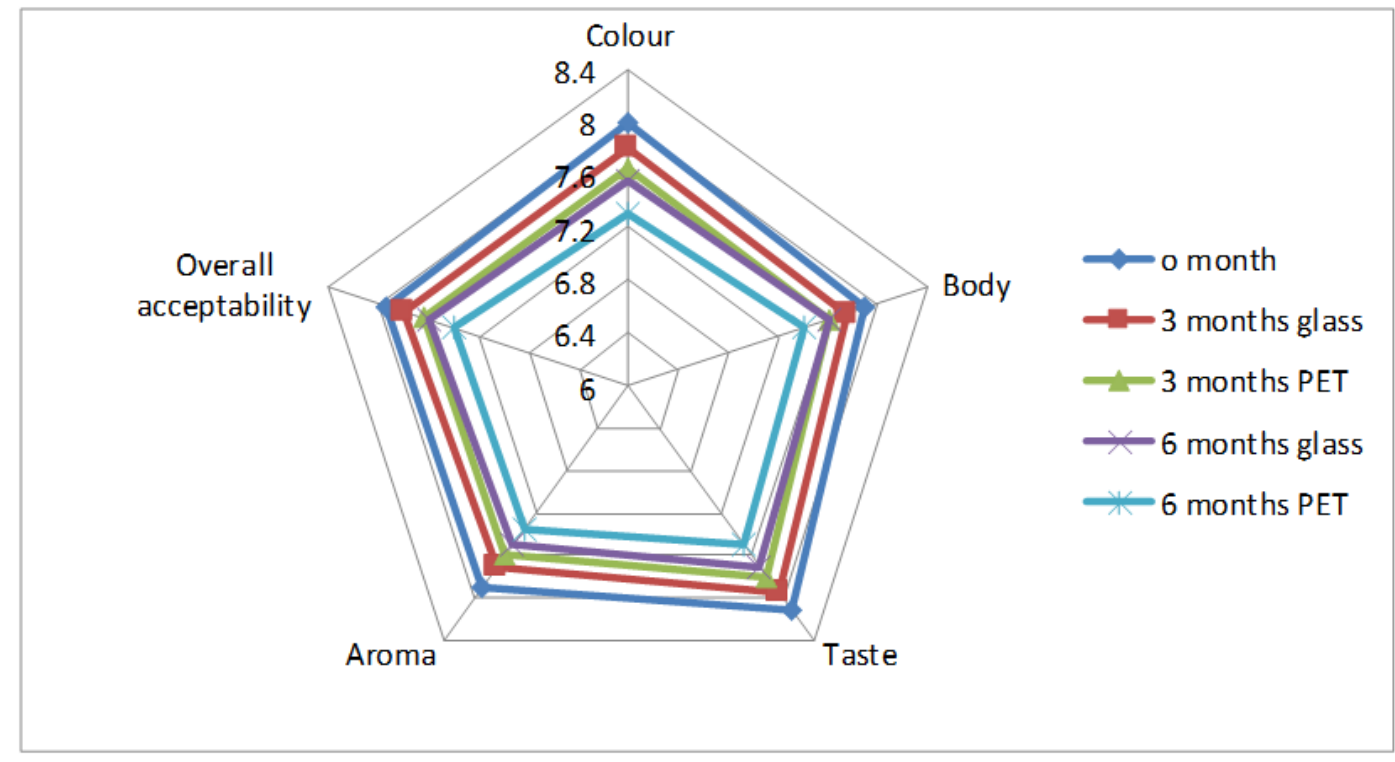

Table.1 Treatment detail of mulberry fruit drink

\begin{tabular}{|c|c|c|c|c|c|c|c|c|c|c|}
\hline Treatment & $\mathbf{T}_{\mathbf{1}}$ & $\mathbf{T}_{\mathbf{2}}$ & $\mathbf{T}_{\mathbf{3}}$ & $\mathbf{T}_{\mathbf{4}}$ & $\mathbf{T}_{\mathbf{5}}$ & $\mathbf{T}_{\mathbf{6}}$ & $\mathbf{T}_{\mathbf{7}}$ & $\mathbf{T}_{\mathbf{8}}$ & $\mathbf{T}_{\mathbf{9}}$ & $\mathbf{T}_{\mathbf{1 0}}$ \\
\hline Juice (\%) & 8 & 10 & 12 & 14 & 16 & 8 & 10 & 12 & 14 & 16 \\
\hline TSS ( $\mathbf{0} \mathbf{B})$ & 12 & 12 & 12 & 12 & 12 & 15 & 15 & 15 & 15 & 15 \\
\hline Acidity (\%) & 0.30 & 0.30 & 0.30 & 0.30 & 0.30 & 0.30 & 0.30 & 0.30 & 0.30 & 0.30 \\
\hline
\end{tabular}


Table.2 Physico-chemical characteristics of different recipes of mulberry RTS beverage

\begin{tabular}{|c|c|c|c|c|c|}
\hline \multirow{3}{*}{$\begin{array}{l}\text { Treatments } \\
\text { (T) }\end{array}$} & \multicolumn{5}{|c|}{ Physico-chemical characteristics } \\
\hline & \multicolumn{2}{|c|}{ Colour (TCU) } & \multirow{2}{*}{$\begin{array}{c}\text { Anthocyanins } \\
(\mathrm{mg} / 100 \mathrm{ml})\end{array}$} & \multirow{2}{*}{$\begin{array}{l}\text { Total phenols } \\
(\mathrm{mg} / 100 \mathrm{ml})\end{array}$} & \multirow{2}{*}{$\begin{array}{l}\text { Ascorbic acid } \\
(\mathrm{mg} / 100 \mathrm{ml})\end{array}$} \\
\hline & $\mathbf{R}$ & $\mathbf{Y}$ & & & \\
\hline 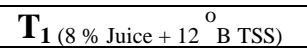 & 4.95 & 0.80 & 1.72 & 12.21 & 1.12 \\
\hline 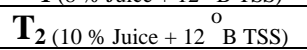 & 5.10 & 0.70 & 2.18 & 15.36 & 1.40 \\
\hline 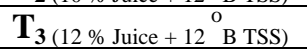 & 5.34 & 0.54 & 2.64 & 18.45 & 1.66 \\
\hline $\mathbf{T}_{\mathbf{4}}$ (14\% Juice + $12^{\circ}{ }_{\text {B TSS })}$ & 5.60 & 0.40 & 2.90 & 21.16 & 1.87 \\
\hline $\mathbf{T}_{\mathbf{5}}$ (16\% Juice + $12{ }^{\circ}{ }_{\text {B TSS })}$ & 5.78 & 0.40 & 3.48 & 24.53 & 2.25 \\
\hline 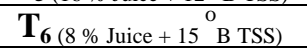 & 5.00 & 0.80 & 1.74 & 12.23 & 1.12 \\
\hline $\mathbf{T}_{7 \text { (10 \% Juice + } 15{ }^{\circ} \text { B TSS) }}$ & 5.20 & 0.70 & 2.16 & 15.37 & 1.38 \\
\hline 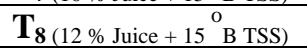 & 5.45 & 0.60 & 2.64 & 18.46 & 1.68 \\
\hline $\mathbf{T}_{\mathbf{9}}$ (14\% Juice + $15^{\circ}{ }^{\circ}$ TSS) & 5.68 & 0.45 & 2.92 & 21.05 & 1.87 \\
\hline $\mathbf{T}_{\mathbf{1 0} \text { (16\% Juice }+15^{\circ}{ }^{\mathrm{B}} \text { TSS) }}$ & 5.80 & 0.40 & 3.47 & 24.54 & 2.25 \\
\hline $\mathrm{CD}_{0.05}$ & 0.08 & 0.07 & 0.06 & 0.13 & 0.09 \\
\hline
\end{tabular}

Table.3 Sensory characteristics (score) of different recipes of mulberry RTS beverage

\begin{tabular}{|c|c|c|c|c|c|}
\hline Treatments (T) & Colour & Body & Taste & Aroma & Overall acceptability \\
\hline $\mathbf{T}_{\mathbf{1}\left(8 \% \text { Juice }+12{ }^{\circ} \text { B TSS }\right)}$ & 7.01 & 5.50 & 5.00 & 6.00 & 6.00 \\
\hline $\mathbf{T}_{\mathbf{2}\left(10 \% \text { Juice }+12{ }^{\circ} \text { B TSS) }\right.}$ & 7.24 & 6.10 & 5.50 & 6.50 & 6.31 \\
\hline $\mathbf{T}_{\mathbf{3} \text { (12 } \% \text { Juice }+12 \stackrel{\circ}{\mathrm{o}} \text { B TSS })}$ & 7.30 & 6.21 & 6.60 & 6.83 & 6.82 \\
\hline $\mathbf{T}_{\mathbf{4}\left(14 \% \text { Juice }+12^{\circ}{ }^{\circ} \text { TSS }\right)}$ & 8.00 & 7.90 & 8.10 & 7.90 & 7.95 \\
\hline 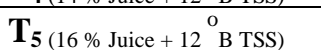 & 7.60 & 6.53 & 7.32 & 7.83 & 7.16 \\
\hline 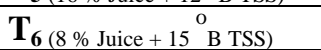 & 7.00 & 5.24 & 5.10 & 6.15 & 6.10 \\
\hline $\mathbf{T}_{7 \text { (10\% Juice }+15{ }^{\circ} \text { B TSS) }}$ & 7.15 & 6.40 & 6.00 & 6.43 & 6.54 \\
\hline $\mathbf{T}_{\mathbf{8}\left(12 \% \text { Juice }+15^{\circ}{ }^{\circ} \text { TSS }\right)}$ & 7.30 & 6.55 & 6.56 & 6.92 & 6.94 \\
\hline $\mathbf{T}_{\mathbf{9}}\left(14 \%\right.$ Juice + $15^{\circ}{ }_{\text {B TSS })}$ & 8.10 & 7.53 & 7.19 & 7.26 & 7.40 \\
\hline $\mathbf{T}_{\mathbf{1 0}}$ (16\% Juice + $15^{\circ}{ }^{\mathrm{B}}$ TSS $)$ & 7.45 & 7.00 & 7.10 & 7.70 & 7.20 \\
\hline $\mathrm{CD}_{0.05}$ & 0.21 & 0.26 & 0.23 & 0.31 & 0.30 \\
\hline
\end{tabular}

Table.4 Physico-chemical and sensory characteristics of standardized recipe

\begin{tabular}{|c|c|c|}
\hline \multicolumn{2}{|c|}{ Characteristics } & Mean and SD \\
\hline \multicolumn{3}{|l|}{ Physico-chemical } \\
\hline \multirow{2}{*}{$\begin{array}{l}\text { Tintometer colour units } \\
\text { (TCU) }\end{array}$} & Red & $5.60 \pm 0.03$ \\
\hline & Yellow & $0.40 \pm 0.05$ \\
\hline \multicolumn{2}{|c|}{ Apparent viscosity (Flow rate in seconds) } & 83.20 \\
\hline \multicolumn{2}{|c|}{ TSS $\left({ }^{\circ} \mathrm{B}\right)$} & $12.00 \pm 0.02$ \\
\hline \multicolumn{2}{|l|}{ Reducing sugars $(\%)$} & $7.90 \pm 0.18$ \\
\hline \multicolumn{2}{|l|}{ Total sugars $(\%)$} & $10.27 \pm 0.28$ \\
\hline \multicolumn{2}{|l|}{ Titratable acidity $(\%)$} & $0.30 \pm 0.02$ \\
\hline \multicolumn{2}{|l|}{$\mathrm{pH}$} & $4.10 \pm 0.01$ \\
\hline \multicolumn{2}{|l|}{ Ascorbic acid $(\mathrm{mg} / 100 \mathrm{ml})$} & $1.87 \pm 0.10$ \\
\hline \multicolumn{2}{|l|}{ Anthocyanins $(\mathrm{mg} / 100 \mathrm{ml})$} & $2.90 \pm 0.06$ \\
\hline \multicolumn{2}{|l|}{ Total Phenols $(\mathrm{mg} / 100 \mathrm{ml})$} & $21.16 \pm 0.04$ \\
\hline \multicolumn{3}{|l|}{ Sensory (Scores) } \\
\hline \multicolumn{2}{|l|}{ Colour } & $8.00 \pm 0.20$ \\
\hline \multicolumn{2}{|l|}{ Body } & $7.90 \pm 0.20$ \\
\hline \multicolumn{2}{|l|}{ Taste } & $8.10 \pm 0.34$ \\
\hline \multicolumn{2}{|l|}{ Aroma } & $7.90 \pm 0.29$ \\
\hline \multicolumn{2}{|l|}{ Overall acceptability } & $7.95 \pm 0.45$ \\
\hline
\end{tabular}




\section{Total sugars}

There was a general increase in total sugars content of mulberry drink during entire storage period (Figure 2). The overall effect of storage period shows that total sugars increased from 10.27 to 11.19 per cent, irrespective of packaging materials and storage conditions. However, overall effect of storage conditions shows that higher (10.88 $\%)$ total sugars were observed in ambient storage conditions as compared to refrigerated storage conditions $(10.66 \%)$.

The higher $(10.84 \%)$ total sugars were recorded in drink packed in PET bottle as compared to glass $(10.70 \%)$ bottle while comparing the overall effect of packaging materials on total sugars of drink. The increased level of total sugar was probably due to conversion of starch and pectin into simple sugars (Kesharwani et al., 2015) and more increase might be due to the faster rate of reaction because of high temperature in ambient conditions. Similar trend of increase in total sugars have been reported by Kesharwani et al., (2015) in Jamun RTS, Tiwari and Deen (2015) in blended RTS from bael and aloe vera, Kannan and Thirumaran (2002) in jamun RTS beverage.

\section{Ascorbic acid}

There was a continuous decrease in ascorbic acid content of drink with advancement of storage period however, decrease was significantly lower under refrigerated conditions (decreased from 1.88 to 1.60 and $1.47 \mathrm{mg} / 100 \mathrm{ml}$ in both glass and PET) as compared to ambient conditions (decreased from 1.88 to 1.10 and $0.86 \mathrm{mg} / 100 \mathrm{ml}$ in both glass and PET). Decrease in ascorbic acid content during storage might be due to its degradation into dehydro-ascorbic acid or furfural. Ascorbic acid is highly sensitive to heat, therefore its degradation was more in ambient conditions. Similar findings have been reported by Chavan et al., (2011) in pomegranate drink. Lower decrease in ascorbic acid of drink packed in glass bottle observed during storage might be due to the slower rate of reactions in it as glass materials absorb heat slower than PET material.

\section{Anthocyanins}

Figure 3 indicate that there was a general decrease in anthocyanins during entire storage period. The overall effect of storage period and storage conditions on anthocyanins content of drink shows that they decreased from 2.90 to $1.89 \mathrm{mg} / 100 \mathrm{ml}$, retained more $(2.56 \mathrm{mg} / 100 \mathrm{ml})$ in refrigerated storage conditions as compared to ambient conditions $(2.18 \mathrm{mg} / 100 \mathrm{ml})$. The higher $(2.47 \mathrm{mg} / 100$ $\mathrm{ml}$ ) anthocyanins content were recorded in drink packed in glass bottle and lower (2.27 $\mathrm{mg} / 100 \mathrm{ml}$ ) in PET bottle, while studying the overall effect of packaging materials on anthocyanins content of this product. Loss of anthocyanins in drink might be due to their high susceptibility to auto oxidative degradation during storage. This could be attributed to light and heat labile nature of the anthocyanins getting affected by temperature during pasteurization and storage and by ambient light conditions during storage. More retention of this parameter in the product might be due to slower rate of auto oxidation of anthocyanins in the product under refrigerated storage conditions as compared to ambient. More retention of anthocyanins of drink packed in glass bottle during storage might be due to the slower rate of reactions in glass bottle than PET as a result of difference in their thermal conductance properties. Similar observations have been reported by Kannan and Thirumaran (2002) in jamun drink (51.3 to $7.5 \mathrm{mg} / 100 \mathrm{ml}$ ), Sonia et al., (2010) in jamun drink (20.6 to $11.2 \mathrm{mg} / 100$ $\mathrm{ml}$ ) and Thakur et al., (2011) in wild pomegranate drink (3.07 to $1.24 \mathrm{mg} / 100 \mathrm{ml}$ ). 


\section{Total phenols}

Figure 4 reveals that there was a general decreasing trend in total phenols content of drink during entire storage period of 6 months which was slower under refrigerated storage conditions than ambient conditions. The overall effect of storage period reveals that total phenols in drink decreased from 21.16 to $16.88 \mathrm{mg} / 100 \mathrm{ml}$ during storage. More decrease was found in drink stored under ambient conditions (decreased from 21.16 to 16.20 and $14.28 \mathrm{mg} / 100 \mathrm{ml}$ in both glass and PET) as compared to refrigerated storage conditions (decreased from 21.16 to 18.94 and $18.12 \mathrm{mg} / 100 \mathrm{ml}$ in both glass and PET). Significant decrease in total phenol content during storage might be due to their involvement in the formation of polymeric compounds, complex formation of phenols with protein and their subsequent precipitations. Slower rate of loss of phenols in refrigerated storage might be due to slower reaction rate in refrigerated conditions as compared to ambient. However, retention of more total phenols of drink in glass bottle may also be the slower reaction rates in glass bottle, as glass material absorb heat at slower rate as compared to PET. Similar observations were recorded by Kanchana et al., (2007) in tamarind drink, Thakur et al., (2011) in wild pomegranate drink and Yadav et al., (2014) in guava and mango drink.

\section{Sensory characteristics}

Data pertaining to all sensory parameters of mulberry drink have been presented in figures 5 and 6.

\section{Colour}

The colour scores of drink decreased significantly during storage and retained better in refrigerated storage conditions than ambient conditions. More decrease was found in drink stored under ambient conditions (decreased from 8.00 to 7.20 and 6.95 in both glass and PET) as compared to refrigerated storage conditions (decreased from 8.00 to 7.55 and 7.30 in both glass and PET). Decrease in colour score during storage might be due to the degradation of colour pigment (anthocyanins) and browning caused by copolymerization of organic acids of the product. The retention of higher colour scores of drink in refrigerated storage conditions might be due to lesser degradation of colour pigment which led the judges to award the higher scores as compared to ambient conditions. Better colour scores retained in glass bottle as compared to PET might be due to the slower rate of degradation of anthocyanins during storage. Decrease in colour scores have also been reported by Din et al., (2011) in functional-dietetic beverage, Chauhan et al., (2012) in herbal RTS beverage and Akhtar et al., (2013) in pomegranate drink.

\section{Body}

There was a general decreasing trend of body score of mulberry drink during storage (Figures 5 and 6). More decrease was found in drink stored under ambient conditions (decreased from 7.90 to 7.10 and 6.80 in both glass and PET) as compared to refrigerated storage conditions (decreased from 7.90 to 7.60 and 7.40 in both glass and PET). Body scores of drink decreased with advancement of storage period and retained higher in refrigerated storage conditions than ambient. The possible reason for decrease in body scores might be due to the formation of precipitates in the product as a result of interactions between phenols and protein as well as the formation of cation complexes with phenols during storage. Our results of body scores are in conformity with the findings of Akhtar et al., (2013) in pomegranate drink. 


\section{Taste}

Figures 5 and 6 show a general decrease in taste score of mulberry drink during storage. More decrease was found in drink stored under ambient conditions (decreased from 8.10 to 7.40 and 6.90 in both glass and PET) as compared to refrigerated storage conditions (decreased from 8.10 to 7.70 and 7.50 in both glass and PET). As far as the packaging material is concerned higher decrease in taste scores of drink was observed in the drink packed in PET bottle than glass bottle. The possible reason for decrease in taste scores might be due to the loss of sugar-acid blend responsible for taste during storage. Similar observations were also noticed by Bisht et al., (2008) in seabuckthorn RTS beverage and Akhtar et al., (2013) in pomegranate drink.

\section{Aroma}

There was a general decreasing trend of aroma score of mulberry drink during storage (Figures 5 and 6). More decrease was found in drink stored under ambient conditions (decreased from 7.90 to 7.10 and 6.85 in both glass and PET) as compared to refrigerated storage conditions (decreased from 7.90 to 7.50 and 7.35 in both glass and PET). The decrease in aroma scores during storage might be due to degradation of aromatic compounds in the product. However, the retention of higher scores in refrigerated conditions might be due to the slower degradation of aromatic compounds which led the judges to award the higher scores to the product in refrigerated conditions as compared to ambient conditions. Similar observations were also observed by Thakur et al., (2011) in wild pomegranate drink and Akhtar et al., (2013) in pomegranate drink.

\section{Overall acceptability}

Figures 5 and 6 show a general decreasing trend in overall acceptability scores of drink during entire storage period. More decrease was found in drink stored under ambient conditions (decreased from 7.95 to 7.10 and 6.70 in both glass and PET) as compared to refrigerated storage conditions (decreased from 7.95 to 7.60 and 7.40 in both glass and PET). However, the drink stored at refrigerated storage conditions was significantly better in overall acceptability scores than in ambient conditions. Decrease in overall acceptability scores might be due to the loss in appearance, flavour compounds and uniformity of the product. Higher overall acceptability scores retained in refrigerated conditions might be due to the minimum loss of colour, uniformity and flavour compounds during storage. Similar decrease in overall acceptability scores have also been reported by Akhtar et al., (2013) in pomegranate drink and Satkar et al., (2013) in bitter gourd RTS beverage.

In conclusion, out of 10 treatment combinations of juice and TSS tried, mulberry RTS beverage prepared with 14 per cent juice $12{ }^{\circ} \mathrm{B}$ TSS and 0.30 per cent acidity $\left(\mathrm{T}_{4}\right)$ was found to be best on the basis of various quality parameters. During storage period of six months RTS beverage was found to be in acceptable condition under both the storage conditions and packaging materials with comparatively minimal changes in its chemical constituents in glass bottle under refrigerated storage condition as compared to PET bottle. The cost of the RTS prepared from mulberry fruit juice was less as comparable to the cost of the similar products in the market. Hence, mulberry fruit can be successfully utilized for the production of good quality and nutritionally enriched products with remunerative cost on commercial scale so that farmers can get additional profit besides sericulture.

\section{Acknowledgment}

The present study has been carried out in 
Department Of Food Science and Technology UHF, Nauni, Solan (H.P.) during the year 2015 and the financial assistance provided by the institution during the study is fully acknowledged.

\section{References}

Akhtar, S., Ali, J., Javed, B., and Khan, F.A. 2013. Studies on the preparation and storage stability of pomegranate juice based drink. Middle-East Journal of Scientific Research, 16(2): 191-195.

Amerine, M.A., Pangborn, R.M., and Roessler, E.B. 1965. Principles of sensory evaluation of food. Academic Press: London. pp. 236-268.

Bisht, R., Sharma, S.K., and Yadav, V.K. 2008. Studies on preparation and storage evaluation of seabuckthorn (Hippophae salicifolia D. Don.) readyto-serve beverage. The Asian Journal of Horticulture, 3(1): 117-121.

Chalke, P.R., Supe, V.S., and Sonavani, P.N. 2012. Effect of packaging and storage temperature on storage behaviour of ready-to-serve beverage of falling unripe mango fruits. The Asian Journal of Horticulture, 7(2): 256-258.

Chauhan, D.K., Puranik, V., and Rai, G.K. 2012. Development of functional herbal RTS beverage. Open Access Scientific Reports, 1(12): 541-545.

Chavan, A., Hussain, A., Patil, M.G., and Imamsaheb, S.J. 2011. Changes in chemical composition of pomegranate (Punica granatum L.) RTS of cv. Kesar as influenced by different per cent of syrup concentrations and storage periods. Indian Horticulture Journal, 1(1): 026-028.

Chon, S.U., Kim, Y.M., Park, Y.J., Heo, B.G., Park, Y.S., and Gorinstein, S. 2009. Antioxidant and proliferative effects of methanol extracts from raw and fermented parts of mulberry plant
(Morus alba L.). European Food Research and Technology, 230: 231237.

Din, A., Bukhari, S.A.H., Salam, A., and Ishfaq, B. 2011. Development of functional and dietetic beverage from bitter gourd. International Journal of Food Safety, 13: 355-360.

Ercisli, S., and Orhan, E. 2007. Chemical composition of white, red and black mulberry fruits. Food Chemistry, 103: 1380-1384.

Gupta, R., Malav, M., Kushwaha, N.K., and Pandey, A. 2015. Studies on organoleptic qualities of orange based blended ready-to-serve beverages. The Bioscan, 10(3): 1041-1043.

Jain, V., Tewari, D.L., Sharma, H.V., and Saxsena, R.R. 1996. Evaluation of late maturing mango varieties for the preparation of beverages as nectar and RTS. Indian Food Packer, 50: 9-14.

Kanchana, S., Vanithasri, J., Banumathi, P. and Kumar, S. 2007. Processing of Tamarind ready to serve beverages. Beverage and Food World, 34(10): 7172.

Kannan, S., and Thirumaran, A.S. 2002. Studies on storage behaviour of jamun products. Beverage and Food World, 29(3): 32-33.

Kesharwani, A., Dikshit, S.N., Kumar, K., Thakur, P., and Chandel, N. 2015. Studies on physico-chemical composition of Jamun and changes in chemical composition of RTS beverage during storage. The Ecoscan, 7: 379383.

Mahony, M.O., 1985. Sensory evaluation of food: statistical methods and procedures. Marcel Dekker: New York. pp. 168-169.

Pushpa, T.H., Jagadeesh, S.L., and Suresha, G.J. 2016. Influence of blending of natural extracts on physicochemical and sensory qualities of aloe vera squash. 
The Bioscan, 11(1): 113-117.

Rajanna, K.M.L., and Shivanna, M. 2008. Preparation and quality analysis of unfermented mango (cv. Raspur) beverages. The Asian Journal of Horticulture. 3(2): 427-428.

Ranganna, S., 2009. Handbook of analysis and quality control for fruit and vegetable products. Second ed. Tata McGraw Hill, New Delhi, pp. 1112.

Satkar, K.P., Kotecha, P.M., and Thorat, S.S. 2015. Process standardization for preparation of health drink from bittergourd. Beverage and Food World, 42(2): 50-52.

Satkar, K.P., Kulthe, A.A., and Chalke, P.R. 2013. Preparation of bitter gourd readyto-serve beverage and effect of storage temperature on its keeping quality. The Bioscan, 8(1): 115-117.

Singelton, V.L., and Rossi, J.A. 1965. Colorimetry of total phenolics with phosphomolybedic phosphotungstic acid reagent. American Journal of Enology and Viticulture, 16: 144-158.

Sonia Gehlot, R., Singh, R., and Yadav, B.S. 2010. Changes in chemical constituents and overall acceptability of jamun ready-to- serve (RTS) drink and nectar during storage. Haryana Journal of Horticultural Sciences, 39(1\&3): 142144.
Thakur, N.S., Dhaygude, G.S., and Joshi, V.K. 2011. Development of wild pomegranate drink and its evaluation during storage. International Journal of Food and Fermentation Technology, 1(2): 237-246.

Tiwari, D.K., and Deen, B. 2015. Preparation and storage of blended Ready-to-serve beverage from Bael and Aloe vera. The Bioscan, 10(1): 113-116.

Yadav, P., Neelima, G., and Kumar, S. 2014 ${ }^{\mathrm{a}}$. Improved shelf stability of mulberry juice by combination of preservatives. Indian Journal of Natural Products and Resources, 5(1): 62-66.

Yadav, S., Gehlot, R., Siddiqui, S., and Grewal, R.B. 2014 ${ }^{\mathrm{b}}$. Changes in chemical constituents and overall acceptability of guava-mango Ready-toServe (RTS) drink and squash. Beverage and Food World, 41(4): 3033.

Zafar, M.S., Muhammad, F., Javed, I., Akhtar, M., Khaliq, T., Aslam, B., Waheed, A., Yasmin, R., and Zafar, H. 2013. White mulberry (Morus alba): A brief phytochemical and pharmacological evaluations account. International Journal of Agriculture and Biology, 15(3): 612-62.

\section{How to cite this article:}

Hamid, N.S. Thakur, Pradeep Kumar and Abhimanyu Thakur. 2017. Studies on Preparation and Preservation of Ready-To-Serve (RTS) Beverage from Underutilized Mulberry (Morus $a l b a$ L.) Fruits and Its Quality Evaluation during Storage. Int.J.Curr.Microbiol.App.Sci. 6(9): 1067-1079. doi: https://doi.org/10.20546/ijcmas.2017.609.128 